\title{
Intrapancreatic true aneurysm treated by laparoscopic spleen- preserving distal pancreatectomy: Case Report and review of literature
}

\author{
Nikdokht Rashidian ${ }^{1 *}$, Maziar Faridi ${ }^{2}$, Amir Ashkan Adman ${ }^{1}$ and Hossein Fahimi ${ }^{2}$ \\ ${ }^{1}$ Department of Surgery, Firoozgar General Hospital, Iran University of Medical Sciences, Tehran, Iran \\ ${ }^{2}$ Department of Surgery, Iranmehr Hospital, Tehran, Iran
}

\begin{abstract}
True intrapancreatic aneurysm is an extremely rare entity and like other rare conditions, doubts still persist about its optimal management. There are few reports of laparoscopic resection for peripancreatic aneurysm, along with splenectomy, but to the best knowledge of the authors, there is just one case report of intrapancreatic true aneurysm that has been treated with open distal pancreatectomy and concomitant splenectomy.
\end{abstract}

Here we report a rare case of intrapancreatic true aneurysm in the pancreas tail, which was not distinguishable from pancreas solid mass by radiologic imaging. The patient underwent a successful laparoscopic spleen-preserving distal pancreatectomy for aneurysm resection.

This case illustrates that laparoscopic resection is a feasible and safe option for treatment of intrapancreatic true aneurysm.

\section{Introduction}

True aneurysm of peripancreatic arteries is an infrequent condition and accounts for only $2 \%$ among all visceral artery aneurysms, although pseudoaneurysms of peripancreatic arteries are more common in association with pancreatitis [1]. Despite its unusual occurrence, the rupture risk resulting in high rate mortality makes it a considerable concern [2]. Since most data in literature are coming from case reports with few relevant information, its treatment of choice remains to be determined.

Recent advances in minimally invasive techniques have made it advantageous in treating visceral aneurysms.

\section{Case report}

A 72-year-old never-smoking female presented with a 2-month history of constant vague epigastric pain. No other relevant symptom was noted. Her medical history was unremarkable and physical examination was not contributory.

An ultrasound examination and abdominal CT-Scan revealed a well-defined $3 \times 2 \mathrm{~cm}$ large mass lesion in pancreas tail (Figure 1). Although there was a significant arterial enhancement inside the lesion, it wasn't clear enough to be discerned of pancreas solid mass. A multidisciplinary discussion among general surgeon, gastrointestinal specialist and interventional radiologist resulted in the possible differential diagnosis of pancreatic tail tumor or aneurysm, since we couldn't rule out pancreas solid mass, radiologic intervention was not reasonable, and she was subjected to surgery.

\section{Technique}

Under general anesthesia, the patient was placed in right lateral decubitus position then the $10 \mathrm{~mm}$ camera port was inserted in the umbilicus and intra-abdominal pressure was set at $12 \mathrm{~mm} \mathrm{Hg}$. The other two $5 \mathrm{~mm}$ and $12 \mathrm{~mm}$ working ports were placed in ergonomic configuration. Superficial abdominal exploration was unremarkable. The greater omentum was divided below the gastroepiploic arch and the pancreas was explored through the lesser sac. A solid mass of approximately $3 \mathrm{~cm}$ in diameter was found in the pancreas tail, which was completely intrapancreatic. The pancreas was mobilized out of the retroperitoneum by incising the peritoneum from the inferior edge of the pancreas to the inferior pole of the spleen. There was a sizable vascular pedicle in inferior edge of pancreas, which was probably originated from inferior pancreaticodeudenal artery. Considering the aneurysm inflow, it was ligated and secured using hemolock clips. The pancreatic tail was mobilized and retracted medially. The splenic artery and vein were identified and preserved. A linear-cutter-stapling device was then placed across the pancreas at the selected resection line, keeping a safe margin to the lesion (Figure 2). The spleen was kept intact, and arterial blood flow and venous drainage were evaluated after aneurysmal ligation by visualizing normal color and consistency of spleen. The resected specimen was placed in retrieval bag and extracted. A drain was placed in the bed of the pancreatic dissection and drawn out through the port site.

Postoperative recovery of the patient was uneventful, while the drain was removed, and the patient stepped out on the third and fourth

Correspondence to: Nikdokht Rashidian, Department of Surgery, Firoozgar General Hospital, Iran University of Medical Sciences, Tehran, Iran, Tel: +989121204573; Email: niki_rashidian@yahoo.com

Key words: peripancreatic arteries, aneurysm resection, distal pancreatectomy

Received: February 08, 2018; Accepted: February 24, 2018; Published: February 28,2018 


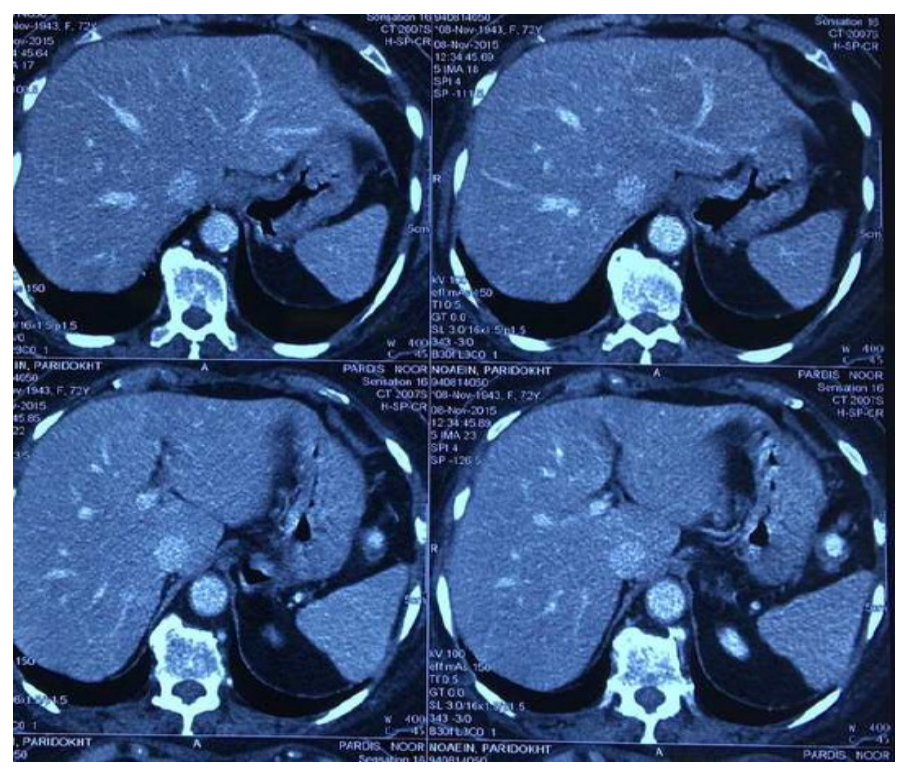

Figure 1. Abdominal CT-Scan revealing a well-defined mass lesion in pancreas tail.

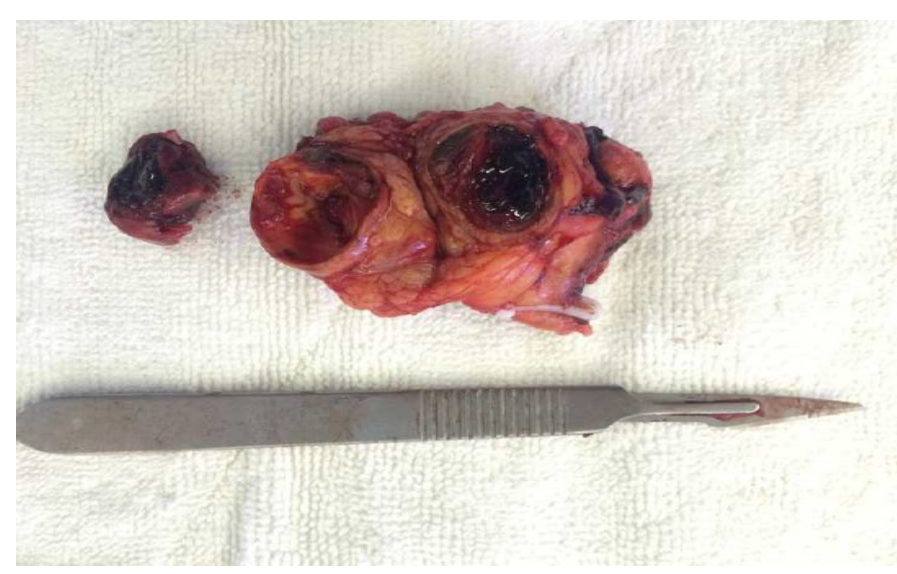

Figure 2. The surgical specimen.

postoperative day respectively. Pathological examinations revealed true intrapancreatic aneurysm. The patient remained asymptomatic 3 months after the operation.

\section{Discussion and conclusion}

Nowadays visceral artery aneurysms are more frequently diagnosed due to significant advances in imaging modalities and the liberal use and availability of them. Amongst all, peripancreatic arterial aneurysms are rare but the potential risk of life-threatening rupture makes them important pathology [3]. Peripancreatic artery aneurysms are the aneurysms which involve gastroduodenal artery or pancreaticoduodenal arteries [4]. Since peripancreatic aneurysms are infrequent, their pathophysiology is not well described, although it seems to be in relation with increased blood flow and pressure in the celiac axis [5]. The clinical characteristics and likelihood of rupture are remained obscure as well. It appears reasonable to envisage that they are simulating splenic artery aneurysm's feature. Accordingly, indications of treatment include exceeding in diameter more than $2 \mathrm{~cm}$, pregnancy and all women in childbearing age [6].

In most cases of visceral artery aneurysms either endovascular embolization or surgical ligation is all that is required, 2 but in case of intrapancreatic lesions, there is a broad differential diagnosis spectrum, which subsequently demands more evaluation and tailored treatment [7]. In this case we had an intrapancreatic aneurysm that was not distinguishable from pancreas tumor by imaging modalities, therefore surgical exploration was mandatory.

Traditionally open exploration and aneurysmal resection with or without splenectomy was the only available surgical option. Since 1993 that saw et al. [8] have reported the first laparoscopic-assisted management of splenic artery aneurysm, there are more laparoscopic attempt reports in treatment of visceral artery aneurysms. With more advancement in laparoscopic technique, spleen-preserving aneurysm resection was tried successfully, considering this fact that if it's feasible practically, spleenpreserving distal pancreatectomy is preferred over concomitant splenectomy because of reducing postoperative infections and pancreatic fistulae and lowering the cancer risk [9].

In experienced hand, especially with fully understanding of pancreas and spleen anatomy and surgical technique, laparoscopic approach to peripancreatic aneurysm is feasible and could be considered as a treatment of choice.

\section{References}

1. de Perrot M, Berney T, Deléaval J, Bühler L, Mentha G, et al. (1999) Management of true aneurysms of the pancreaticoduodenal arteries. Ann Surg 229: 416-420. [Crossref]

2. Moore E, Matthews MR, Minion DJ, Quick R, Schwarcz TH, et al. (2004) Surgical management of peripancreatic arterial aneurysms. J Vasc Surg 40: 247-253. [Crossref]

3. Van Doesburg IA, Boerma D, van Leersum M, van Ramshorst B (2009) Aneurysm of the Superior Posterior Pancreatic-Duodenal Artery Presenting with Recurrent Syncopes. Case Rep Gastroenterol 28: 230-234. [Crossref]

4. Shanley CJ, Shah NL, Messina LM (1996) Uncommon splanchnic artery aneurysms pancreaticoduodenal, gastroduodenal, superior mesenteric, inferior mesenteric, and colic. Ann Vasc Surg 10: 506. [Crossref]

5. Kallamadi R, Demoya MA, Kalva SP (2009) Inferior Pancreaticoduodenal Artery Aneurysms in Association with Celiac Stenosis/Occlusion. Semin Intervent Radiol 26 : 215-223. [Crossref]

6. Diamantopoulos GI, Kapiris SA, Mavromatis TN (2004) Intrapancreatic True Arterial Aneurysm Mimicking Pancreatic Tumor. J Gastrointest Surg 8: 757-758. [Crossref]

7. To'o KJ, Raman SS, Yu NC, Kim YJ, Crawford T, et al. (2005) Pancreatic and Peripancreatic Diseases Mimicking Primary Pancreatic Neoplasia. Radiographics 25: 949-965. [Crossref]

8. Saw EC, Ku W, Ramachandra S (1993) Laparoscopic resection of a splenic artery aneurysm. J Laparoendosc Surg 3: 167-171. [Crossref]

9. Inoko K, Ebihara Y, Sakamoto K, Miyamoto N, Kurashima Y, et al. (2005) Strategic Approach to the Splenic Artery in Laparoscopic Spleen-preserving Distal Pancreatectomy. Surg Laparosc Endosc Percutan Tech 25: 122-125. [Crossref]

Copyright: (C2018 Rashidian N. This is an open-access article distributed under the terms of the Creative Commons Attribution License, which permits unrestricted use, distribution, and reproduction in any medium, provided the original author and source are credited. 